\title{
Característica físico-química e sensorial de geleia elaborada com polpa e suco de acerola
}

\author{
Physicochemical and sensory characteristics of jam \\ produced with acerola pulp and juice
}

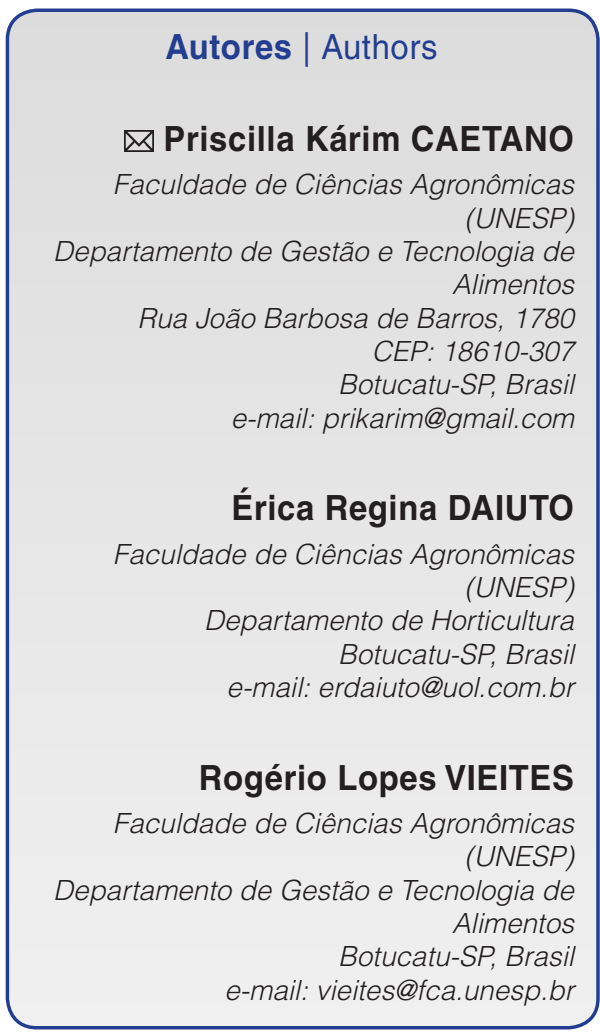

$\triangle$ Autor Correspondente / Corresponding Author

Recebido / Received: 07/07/2010 Aprovado / Approved: 24/01/2011 Publicado / Published: set./2012

\section{Resumo}

A acerola destaca-se por seu teor de vitamina C e seu potencial para industrialização. Seu aproveitamento é possível em produtos, como compotas, geleias, sucos e suplementos alimentares, entre outros. O objetivo deste trabalho foi desenvolver uma formulação de geleia a partir do suco e da polpa de acerola, além de verificar a característica físico-química e sensorial do produto. As geleias foram elaboradas com o suco integral e a polpa de acerola. As formulações foram T1 suco/açúcar (1/1); T2 suco/açúcar (0,6/0,4); T3 polpa/açúcar (1/1), e T4 polpa/ açúcar $(0,6 / 0,4)$, sendo todas com $1 \%$ de pectina. O processo de fabricação foi manual em tachos abertos de aço inoxidável. As avaliações no suco, na polpa e na geleia de acerola foram: $\mathrm{pH}$, acidez, umidade, açúcar redutor, açúcar redutor total, ácido ascórbico e sólidos solúveis ( ${ }^{\circ}$ Brix). Para suco e polpa, determinaram-se também teor de sólidos insolúveis em água, ratio e cinzas. Os resultados da avaliação físico-química da polpa e do suco de acerola mostraram características favoráveis à elaboração de geleia, não sendo necessária a adição de ácidos. A avaliação físico-química das geleias foi adequada ao produto, mantendo-se um teor de ácido ascórbico de 599,25 a 664,79 mg. As geleias elaboradas com polpa/açúcar $(0,6 / 0,4)$ apresentaram coloração mais intensa com maiores valores de luminosidade e componentes de cor $a^{*}$ e $b^{*}$. Em todos os aspectos sensoriais avaliados, os resultados foram desejáveis e as geleias obtiveram boa aceitabilidade. A relação polpa/açúcar 0,6/0,4 apresentou melhor aceitação em relação às demais formulações.

Palavras-chave: Aceitação; Malphigia emarginata; Processamento.

\section{Summary}

Acerola stands out for its vitamin C content and potential for industrialization. Its use is possible in products such as preserves, jams, juices and food supplements, amongst others. The objective of this study was to develop a jam formulation from the juice and pulp and verify the physicochemical and sensory characteristics of the product. Jams were prepared with whole acerola juice and pulp. The formulations were T1 pulp/sugar (1/1), T2 juice/sugar (0.6/0.4), T3 juice/ sugar (1/1) and T4 pulp/sugar (0.6/0.4), all with $1 \%$ of pectin. The evaluations carried out on the acerola juice, pulp and jam were: $\mathrm{pH}$, acidity, moisture, reducing sugars, total reducing sugar, ascorbic acid and soluble solids ( $\left.{ }^{\circ} \mathrm{Brix}\right)$. For the juice and pulp the water insoluble solids, ash content and ratio were also determined. The results of the physicochemical evaluations of the acerola pulp and juice showed favorable characteristics for jam preparation, the addition of acid not being necessary. The physiochemical evaluation of the jam showed appropriate results for this product, retaining an ascorbic acid content of from 599.25 to $664.79 \mathrm{mg}$. The jams elaborated with a pulp/sugar ratio of $(0.6 / 0.4)$ presented a more intense coloration than the others, with higher values for brightness and the color components $a^{*}$ and $b^{*}$. In all the sensory aspects evaluated, the results were desirable and the jams well accepted. The formulation with a 0.6/0.4 pulp/ sugar ratio, was better accepted than the other formulations. 


\section{Introdução}

A acerola tem boa aceitação no mercado em razão, especialmente, do seu elevado teor de ácido ascórbico (vitamina C), bem como das suas características nutricionais, associado ao sabor e à textura agradáveis ao paladar do consumidor. Destaca-se também por conter carotenoides e fitoquímicos, como as antocianinas. De acordo com Aguiar (2001), o teor de $\beta$-caroteno da acerola, quando associado ao alto conteúdo de vitamina C, a torna um fruto de grande importância nutricional.

A acerola apresenta potencial para industrialização, sendo sua utilização na forma de compotas, geleias, enriquecimento de sucos e de alimentos dietéticos, e na forma de alimentos nutracêuticos, como comprimidos ou cápsulas, empregados como suplemento alimentar, chás, bebidas para esportistas, barras nutritivas e iogurte (CARPENTIERI-PÍPOLO et al., 2002). Também é consumida na forma de suco (integral, concentrado, liofilizado), licor, soft drink, bombons, goma de mascar, néctares, purê, sorvetes, cobertura de biscoitos, refrigerantes, etc. (CARVALHO, 2000).

As frutas tropicais são altamente perecíveis, deteriorando-se em poucos dias. Esse fato dificulta sua comercialização, na forma in natura, a grandes distâncias. Estima-se que, nas áreas tropicais e subtropicais, as perdas pós-colheita de frutas e hortaliças variam entre 15 e $50 \%$, principalmente por manuseio e preservação inadequados (CHITARRA e CHITARRA, 2005). A acerola é uma dessas frutas tropicais e, aliado ao seu valor nutricional, torna-se importante o desenvolvimento de produtos com essa matéria-prima. A transformação de frutas em produtos possibilita absorver grande parte da colheita, favorecendo o consumo de frutas durante o ano todo e a redução do desperdício de alimentos.

As geleias podem ser consideradas como o segundo produto em importância comercial para a indústria de conservas de frutas brasileiras (SOLER, 1991). Diversas frutas, provenientes de pomares comerciais, são utilizadas na industrialização de geleias, tais como morango, uva, maçã e laranja, entre outras. A literatura relata pouca pesquisa sobre formulação, preparo e características sensoriais de geleia de acerola. Mélo (1999) realizaram estudo sobre formulação, avaliação físico-química e sensorial de geleia mista de pitanga e acerola, e Negrete (2001) avaliou um processo de elaboração a vácuo para a geleia de acerola, analisando também a vida de prateleira.

Este trabalho teve como objetivo desenvolver uma formulação de geleia a partir do suco e da polpa de acerola, além de verificar a característica físico-química e sensorial do produto.

\section{Material e métodos}

\subsection{Materiais}

As acerolas da variedade olivier foram colhidas manualmente num pomar comercial implantado em 1997, no município de Junqueirópolis, na região chamada de Nova Alta Paulista, Estado de São Paulo. Foi realizada uma pré-limpeza para retirar os galhos, folhas, pedúnculos, frutas deterioradas e insetos. As frutas amadurecidas foram selecionadas e, posteriormente, lavadas três vezes em água corrente e sanitizadas em solução clorada (1\%) durante 20 min. Após essa etapa, foram extraídos a polpa e o suco integral.

As matérias-primas usadas na fabricação da geleia foram polpa de acerola, suco integral de acerola, açúcar comercial (cristal) e pectina comercial de alta metoxilação (ATM) tipo 8105, cedida pela Braspectina S.A. A pectina em pó foi dispersa em cinco partes de açúcar antes de ser adicionada à polpa ou ao suco de acerola quente a uma temperatura entre 71 e $77^{\circ} \mathrm{C}$.

Os equipamentos utilizados foram despolpadora, prensa e tacho de aço inoxidável.

\subsection{Extração da polpa e do suco integral de acerola}

Após a lavagem e a seleção, foi extraída a polpa com despolpadora descontínua com peneira de malha $0,5 \mathrm{~mm}$. A despolpadora com $5 \mathrm{~kg}$ de fruta in natura foi mantida em funcionamento por $10 \mathrm{~min}$. A extração do suco foi realizada utilizando prensa manual com o uso de um tecido de malha fina, denominado voil, de composição 100\% poliéster, utilizado para prensar alimentos, com finalidade de separar o suco da polpa da fruta. Utilizou-se $1,5 \mathrm{~kg}$ de fruta por batelada, com pressão de duas toneladas (indicada em manômetro). Depois de extraídos, o suco e a polpa foram acondicionados em garrafas plásticas e armazenados em freezer.

\subsection{Caracterização físico-química da matéria-prima}

O suco e a polpa de acerola foram homogeneizados e analisados quanto aos teores de sólidos totais, sólidos solúveis ( ${ }^{\circ}$ Brix), potencial hidrogeniônico $(\mathrm{pH})$, acidez titulável, sólidos insolúveis em água, cinzas, relação sólidos solúveis/acidez titulável (ratio) e umidade, de acordo com Brasil (2005a); açúcar redutor-AR e açúcar redutor total-ART (licor de Fehling), conforme Copersucar (1980), e ácido ascórbico pelo Método de Tillmans modificado, conforme Brasil (2005b).

\subsection{Processamento da geleia}

As geleias foram elaboradas com o suco integral e a polpa de acerola; as formulações avaliadas foram T1 (suco, açúcar 1/1); T2 (suco, açúcar 0,6/0,4); T3 
(polpa, açúcar 1/1), e T4 (polpa, açúcar 0,6/0,4), todas com $1 \%$ de pectina em relação ao peso de açúcar, segundo procedimento utilizado por Krolow (2005). A cocção foi feita em tachos abertos de aço inoxidável, com agitação manual contínua. A polpa foi aquecida até aproximadamente $70^{\circ} \mathrm{C}$ e logo foi adicionado o açúcar. Quando foi adicionado o açúcar, ocorreu a formação de espuma, a qual foi retirada com colher espumadeira no final da cocção.

Próximo ao ponto final de cozimento, com temperatura acima de $100{ }^{\circ} \mathrm{C}$, foi adicionada a pectina e deixou-se chegar à concentração final de sólidos solúveis de $67,5^{\circ}$ Brix, determinada em refratômetro. A temperatura final foi de $103,6^{\circ} \mathrm{C}$ e o tempo para a realização da produção da geleia variou de 45 a 50 min. Após essa etapa, envasou-se a geleia a quente em embalagens de vidro com capacidade para $250 \mathrm{~g}$, previamente esterilizadas a $121{ }^{\circ} \mathrm{C} .15 \mathrm{~min}^{-1}$, sendo então fechadas com tampa de metal e invertidas. A seguir, as geleias foram resfriadas em água até aproximadamente $40{ }^{\circ} \mathrm{C}$ e armazenadas em temperatura ambiente.

\subsection{Características físico-químicas das geleias}

As geleias de acerola foram homogeneizadas e analisadas quanto aos teores de sólidos totais, sólidos solúveis ( ${ }^{\circ}$ Brix), potencial hidrogeniônico e acidez titulável, conforme descrito para a matéria-prima (item 2.3).

\subsection{Cor}

Foram colocados $25 \mathrm{~g}$ de cada geleia analisada em copo de café de polietileno e a cor foi medida em luz branca e temperatura ambiente. A cor foi medida em colorímetro da marca Konica Minolta (Chroma meter, CR 400/410) na faixa de comprimento de onda de 380 a $780 \mathrm{~nm}$. Foi realizada a leitura de refletância com ângulo de observação de $2^{\circ}$ e selecionado o iluminante C. A cor foi expressa pelo sistema de coordenadas retangulares $L^{*} a^{*} b^{*}$ conforme a CIE (Comission Internatinale de $E^{\prime}$ 'clairage), segundo a qual $L^{*}$ expressa em porcentagem valores de luminosidade $(0 \%=$ negro e $100 \%=$ branco $)$, $a^{*}$ representa as cores vermelha $(+)$ ou verde $(-)$ e $b^{*}$ as cores amarela $(+)$ ou azul $(-)$.

\subsection{Análise sensorial}

A avaliação sensorial foi realizada utilizando-se o método de aceitação (BRASIL, 2005a), em condições laboratoriais com um grupo de 60 provadores não treinados escolhidos ao acaso. Os provadores foram instruídos a preencher uma ficha, avaliando o produto nos atributos de aparência, odor, corte, espalhamento, sabor e avaliação geral, de acordo com a escala hedônica variando de um (desgostei muitíssimo) a nove (gostei muitíssimo). Os provadores receberam uma amostra de geleia de acerola em copos descartáveis de café (polietileno), um copo de água e bolacha de água e sal. Os testes foram conduzidos sob luz branca em um laboratório próprio para a análise.

A análise estatística utilizada foi o teste t de Student para comparação de médias da polpa e do suco, e a análise de variância, seguida do teste de Tukey, para comparação dos tratamentos. O nível de significância utilizado foi de $5 \%$ e o programa estatístico utilizado foi o SPSS versão 1.7 (NIE et al., 1975).

Os resultados foram apresentados em forma de média e desvio padrão.

\section{Resultados e discussão}

\subsection{Caracterização físico-química da matéria-prima}

Foi verificada diferença significativa para a maioria dos parâmetros físico-químicos analisados para polpa e suco de acerola, exceto para os valores de $\mathrm{pH}$, açúcares redutores e teores de ácido ascórbico (Tabela 1).

Tabela 1. Média e desvio padrão referentes à caracterização físico-química e química de polpa e suco de acerola.

\begin{tabular}{|c|c|c|c|}
\hline \multirow[t]{2}{*}{ Análises } & \multicolumn{3}{|c|}{ Máteria-prima } \\
\hline & Suco & Polpa & Valor $p$ \\
\hline${ }^{\circ}$ Brix & $7,61^{b} \pm 0,04$ & $7,93^{a} \pm 0,03$ & $<0,001$ \\
\hline Acidez titulável (g ácido cítrico. $100 \mathrm{~g}^{-1}$ ) & $0,84^{a} \pm 0,00$ & $0,94^{b} \pm 0,02$ & $<0,001$ \\
\hline Ratio & $0,57^{a} \pm 0,00$ & $0,53^{b} \pm 0,01$ & $<0,001$ \\
\hline Potencial hidrogeniônico & $3,47^{a} \pm 0,01$ & $3,44^{b} \pm 0,02$ & 0,035 \\
\hline Açúcar redutor (\%) & $5,17^{a} \pm 0,07$ & $5,26^{a} \pm 0,18$ & 0,20 \\
\hline Açúcar redutor total (\%) & $4,82^{b} \pm 2,64$ & $5,14^{\mathrm{a}} \pm 0,02$ & $<0,001$ \\
\hline Umidade (\%) & $92,49^{a} \pm 0,28$ & $91,17^{b} \pm 0,53$ & $<0,001$ \\
\hline Cinzas (\%) & $0,31^{b} \pm 0,00$ & $0,42^{\mathrm{a}} \pm 0,01$ & $<0,001$ \\
\hline Sólidos insolúveis (\%) & $0,67^{b} \pm 1,14$ & $4,23^{a} \pm 0,11$ & $<0,001$ \\
\hline Ácido ascórbico (mg.100 mL-1) & $1054^{a} \pm 23,79$ & $1054^{a} \pm 8,99$ & 1,00 \\
\hline
\end{tabular}

Teste t de Student (nível de $5 \%$ de significância). 
Os teores de sólidos solúveis ( $\left.{ }^{\circ} \mathrm{Brix}\right), \mathrm{pH}$ e acidez estão de acordo com Gomes et al. (2000), que avaliaram os principais genótipos de aceroleiras e o pH variou de 3,07 a 3,82 e o teor de sólidos solúveis, de 5,25 a 8,58. Gonzaga Neto et al. (1999) caracterizaram clones de aceroleira e verificaram que o $\mathrm{pH}$ variou de 3,11 a 3,70 e os valores de acidez, de 0,79 a $1,90 \%$. Os autores citaram que esses valores dependem do estádio de maturação da fruta.

Os valores de açúcares redutores e açúcares redutores totais apresentaram-se próximos, demonstrando que a polpa e o suco não acumulam sacarose e seus açúcares são provavelmente a glicose e a frutose. Conforme Chitarra e Chitarra (2005), o teor de açúcares constitui de 65 a $85 \%$ do teor de sólidos solúveis ( ${ }^{\circ}$ Brix). Lago et al. (2006) citam que a presença desses açúcares é um fator de qualidade na aceitação da fruta in natura ou processada, apresentando também importância nutricional.

O teor de sólidos insolúveis obtido para a polpa foi significativamente maior em relação ao suco; tal resultado deve-se à quantidade de sólidos em suspensão que atravessou a peneira de malha $0,5 \mathrm{~mm}$. A despolpadora desintegra as frutas, produzindo detritos celulares. Essas partículas passam livremente pela malha da peneira, permanecendo na polpa. Diversamente, na prensagem, as frutas são esmagadas, mas não trituradas, permanecendo praticamente íntegras, sem gerar os fragmentos celulares. Além disso, o tecido sintético voil usado para acondicionar as acerolas durante a prensagem tinha malha de aproximadamente $0,1 \mathrm{~mm}$, que reteve as partículas maiores geradas no processo. Para os teores de cinzas, os resultados estão de acordo com Chaves et al. (2004), sendo a fração encontrada de $0,43 \%$.

Os teores de ácido ascórbico foram iguais para o suco e a polpa, $1054 \mathrm{mg} .100 \mathrm{~mL}^{-1}$, sendo os valores concordantes com resultados de outros autores. Segundo Paiva et al. (2002), que estudaram melhoramento genético da aceroleira, o teor de ácido ascórbico variou de 1001 a $1600 \mathrm{mg} .100 \mathrm{~mL}^{-1}$. Aragão et al. (1996) encontraram teores de $1040 \mathrm{mg} .100 \mathrm{~mL}^{-1}$ de ácido ascórbico em suco de acerolas maduras.

Gorgatti Netto et al. (1996) avaliaram o teor de ácido ascórbico de acerolas em seis estádios de maturação, classificando o estádio cinco de vermelho e o seis de vermelho escuro. Verificaram que as frutas, nesses estádios, apresentaram concentração de ácido ascórbico variando de 1120 a $1021 \mathrm{mg} .100 \mathrm{~mL}^{-1}$. Os resultados desses autores estão próximos dos encontrados nesta pesquisa, cujo estádio de maturação das acerolas foi igual ao trabalho citado.

\subsection{Caracterização físico-química da geleia de acerola}

O valor de $\mathrm{pH}$ nas geleias variaram de 3,42 a 3,48 (Tabela 2), sendo que apenas o tratamento 4 (polpa, açúcar 0,6/0,4) diferiu estatisticamente dos demais, apresentando menor valor. Jackix (1988) diz que o pH das geleias deve ser de 3,4, sendo que, abaixo de 3,0, ocorre uma tendência a sinérese. Negrete (2001) comprovou que o aumento do pH na fabricação de geleia de acerola não prejudicou a qualidade da geleia, pois teve boa aceitação na análise sensorial. Portanto, oo valores do pH das geleias elaboradas neste trabalho foram adequados ao produto.

Semensato e Pereira (2000) confirmaram que a acerola é uma fruta ácida, demonstrando a possibilidade de sua utilização industrial para a fabricação de geleias e doces, sem a adição de ácidos no processamento. Para a acidez, todas as formulações estão de acordo com a quantidade recomendada e variaram de 0,49 a $0,68 \%$. Sabe-se que a acidez total não deve exceder a $0,8 \%$ e que o mínimo indicado é de 0,3\% (JACKIX, 1988). A Tabela 2 mostra que os valores de acidez foram diferentes para todos os tratamentos e que as formulações de polpa e suco com menor quantidade de açúcar apresentaram menores valores de acidez.

Tabela 2. Caracterização físico-química e química das geleias de acerola.

\begin{tabular}{|c|c|c|c|c|c|}
\hline \multirow[t]{2}{*}{ Análises } & \multicolumn{5}{|c|}{ Tratamentos } \\
\hline & T1 & T2 & T3 & T4 & Valor $\mathbf{p}$ \\
\hline $\mathrm{pH}$ & $3,48^{a} \pm 0,01$ & $3,46^{a} \pm 0,01$ & $3,46^{a} \pm 0,01$ & $3,42^{b} \pm 0,04$ & $<0,001$ \\
\hline Acidez Titulável (g ácido cítrico.100 g ${ }^{-1}$ ) & $0,49^{d} \pm 0,007$ & $0,64^{b} \pm 0,001$ & $0,55^{\mathrm{c}} \pm 0,004$ & $0,68^{\mathrm{a}} \pm 0,009$ & $<0,001$ \\
\hline Sólidos solúveis ( ${ }^{\circ}$ brix) & $67,97^{\mathrm{a}} \pm 0,14^{\mathrm{a}}$ & $66,92^{b} \pm 0,09$ & $67,83^{a} \pm 0,15$ & $67,90^{a} \pm 0,16$ & $<0,001$ \\
\hline Umidade (\%) & $29,79^{d} \pm 0,10$ & $32,56^{a} \pm 0,16$ & $30,27^{c} \pm 0,17$ & $31,21^{b} \pm 0,23$ & $<0,001$ \\
\hline Açúcar redutor (\%) & $24,77^{b} \pm 1,26$ & $32,01^{a} \pm 1,24$ & $21,69^{c} \pm 0,29$ & $32,55^{a} \pm 0,82$ & $<0,001$ \\
\hline Açúcar redutor total (\%) & $62,30^{b} \pm 1,04$ & $65,55^{a} \pm 2,17$ & $54,38^{c} \pm 3,04$ & $60,88^{b} \pm 1,44$ & $<0,001$ \\
\hline Ácido ascórbico (mg.100 mL-1) & $664,79^{a} \pm 3,12$ & $599,25^{c} \pm 23,56$ & $631,5^{b} \pm 15,39$ & $662,58^{a} \pm 23,35$ & $<0,001$ \\
\hline
\end{tabular}

Médias seguidas de pelo menos uma letra em comum não diferem estatisticamente pelo teste Tukey a $5 \%$ de probabilidade, seguidas do desvio padrão. T1 (suco, açúcar 1/1); T2 (suco, açúcar 0,6/0,4); T3 (polpa, açúcar 1/1); T4 (polpa, açúcar 0,6/0,4). 
O teores de sólidos solúveis ( ${ }^{\circ}$ Brix) variaram de 66,92 a 67,97 nas geleias. Os teores encontrados neste trabalho estão de acordo com Soler (1991), ao citar que a concentração de açúcar deve ser em torno de $67,5^{\circ}$ Brix, pois, se o ponto final da geleia for acima desse valor, ocorrerá a formação de cristais; se for abaixo, resultará uma geleia muito mole.

Os valores de umidade foram diferentes para os quatro tratamentos e variaram de 29,79 a $32,56 \%$, sendo os menores valores para as formulações em que se utilizou uma parte de suco ou polpa para a mesma parte de açúcar (1/1); ou seja os tratamentos 1 e 3.

Para os açúcares redutores, os valores médios variaram de 21,69 a $32,55 \%$ e observou-se que os menores valores foram encontrados para formulações (1/1), ou seja, T1 e T3. Para os açúcares redutores totais, os menores valores encontrados foram para a formulação da polpa 1/1. Os valores encontrados estão de acordo com Damiani et al. (2009), que encontraram valores de $63,5 \%$ em geleias de manga formuladas com casca em substituição à polpa, e com Assis (2007), que encontrou 68,47\% para açúcares totais, em geleia de caju.

As concentrações de ácido ascórbico encontradas variaram de 599,25 a 664,79 mg de ácido ascórbico em $100 \mathrm{~g}$ de geleia; verifica-se que, após o cozimento, há uma perda de aproximadamente 50\% do teor de ácido ascórbico em relação aos valores originais na polpa e no suco de acerola, que eram de $1054 \mathrm{mg} .100 \mathrm{~mL}^{-1}$. Observou-se que o menor valor de ácido ascórbico foi encontrado para a geleia feita com suco (T2).
Mustard (1946) processou geleia de acerola e determinou a concentração de ácido ascórbico pelo método colorimétrico. As médias das análises foram de 683 mg a 509 mg de ácido ascórbico para 100 g de geleia; no referido trabalho, a autora relata a quantidade de ácido ascórbico e cita que três colheres de chá poderiam suprir a IDR (ingestão diária recomendada) de vitamina C. Portanto, embora quantitativamente a perda de ácido ascórbico tenha sido considerada razoável após o processamento, não chega a comprometer o valor nutricional do produto, uma vez que o teor de ácido ascórbico do mesmo é comparável aos de alimentos considerados ricos nesse nutriente. Figura 1

A coloração das geleias pode ser observada na

Os valores de luminosidade variaram de 12,13 a $23,79 \%$, sendo o menor valor para o T3 e o maior para o T4.

O parâmetro de cor a $(+)$ indica a presença do componente de cor vermelha nas geleias e variou de 3,42 a 5,91, sendo o maior valor detectado nas geleias do T3. Já o parâmetro de cor b (+) indica a presença do componente de cor amarela nas geleias e variou de 5,18 a 13,92. Observou-se maior presença dos componentes de cores vermelha e amarela nas formulações de polpa.

Os resultados obtidos na avaliação sensorial de aparência, odor, sabor, corte, espalhamento e avaliação geral são apresentados na Tabela 3.

Para o atributo aparência, observou-se que não ocorreu diferença entre as geleias dos quatro tratamentos.
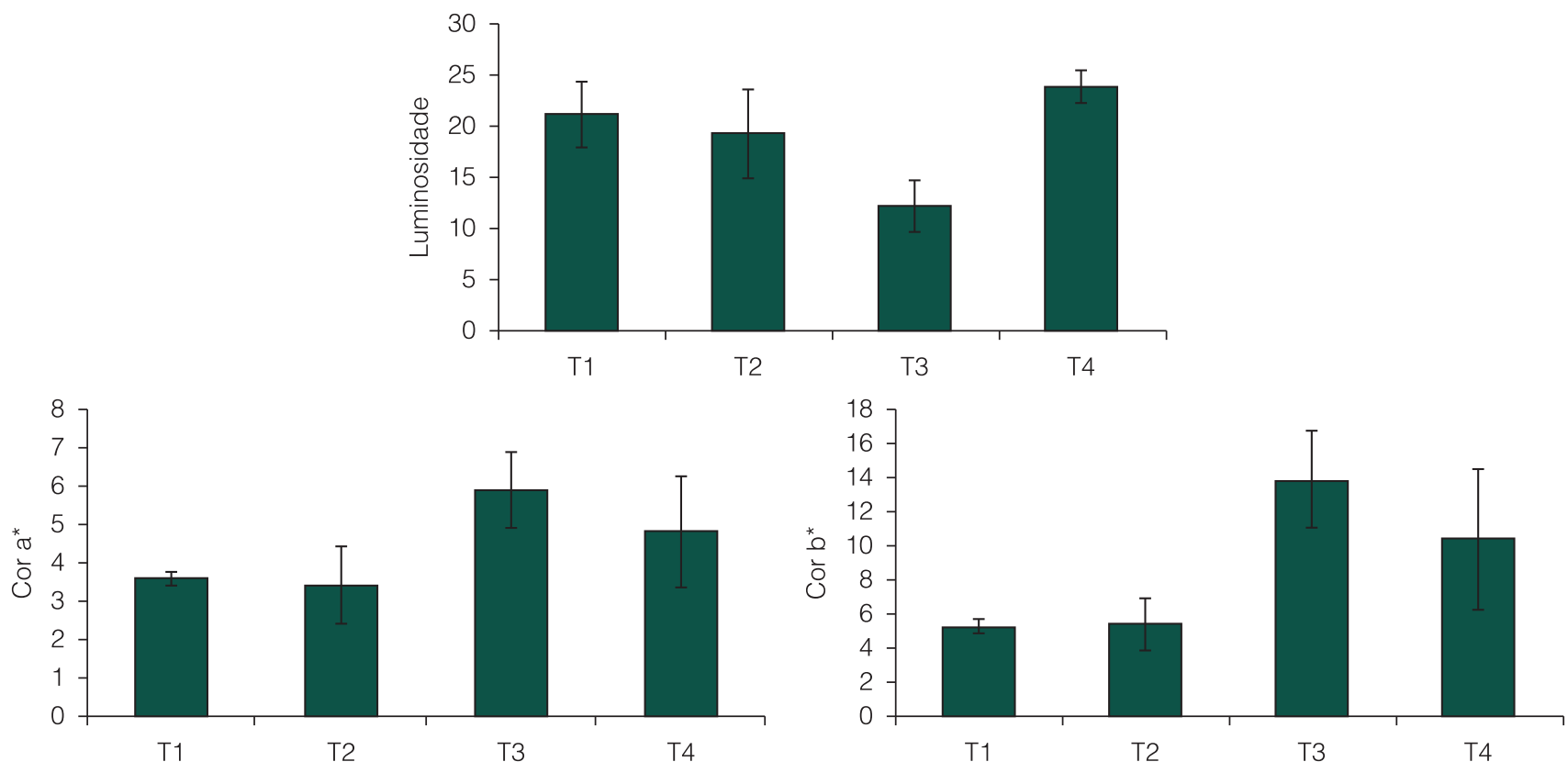

Figura 1. Valores de luminosidade (L), cor $a^{*}$ e b* em geleias de acerola. T1 (suco, açúcar 1/1); T2 (suco, açúcar 0,6/0,4); T3 (polpa, açúcar 1/1); T4 (polpa, açúcar 0,6/0,4). 
Característica físico-química e sensorial de geleia elaborada com polpa e suco de acerola

CAETANO, P. K. et al.

Tabela 3. Resultados da análise sensorial das geleias de acerola.

\begin{tabular}{lccccc}
\multicolumn{1}{c}{ Análises } & \multicolumn{1}{c}{ T1 } & T2 & Tratamentos & T4 & Valo p \\
\hline Aparência & $7,43^{\mathrm{a}} \pm 1,40$ & $7,47^{\mathrm{a}} \pm 1,49$ & $7,58^{\mathrm{a}} \pm 1,20$ & $6,98^{\mathrm{a}} \pm 1,27$ & 0,08 \\
Odor & $7,00^{\mathrm{a}} \pm 1,36$ & $6,55^{\mathrm{a}} \pm 1,39$ & $6,55^{\mathrm{a}} \pm 1,22$ & $6,53^{\mathrm{a}} \pm 1,58$ & 0,19 \\
Corte & $7,07^{\mathrm{a}} \pm 1,72$ & $6,92^{\mathrm{a}} \pm 1,76$ & $5,93^{\mathrm{b}} \pm 1,89$ & $7,28^{\mathrm{a}} \pm 1,38$ & $<0,001$ \\
Espalhamento & $7,42^{\mathrm{a}} \pm 1,53$ & $7,73^{\mathrm{a}} \pm 1,10$ & $7,48^{\mathrm{a}} \pm 1,66$ & $7,52^{\mathrm{a}} \pm 1,47$ & 0,66 \\
Sabor & $6,92^{\mathrm{ab}} \pm 1,49$ & $6,97^{\mathrm{ab}} \pm 1,69$ & $6,25^{\mathrm{b}} \pm 1,71$ & $7,08^{\mathrm{a}} \pm 1,27$ & 0,01 \\
Avaliação geral & $7,43^{\mathrm{b}} \pm 1,14$ & $7,55^{\mathrm{ab}} \pm 1,02$ & $7,28^{\mathrm{b}} \pm 1,33$ & $7,62^{\mathrm{a}} \pm 1,15$ & 0,42 \\
\hline
\end{tabular}

Médias seguidas de pelo menos uma letra em comum não diferem estatisticamente pelo teste Tukey a $5 \%$ de probabilidade, seguidas de desvio padrão. T1 (suco, açúcar 1/1); T2 (suco, açúcar 0,6/0,4); T3 (polpa, açúcar 1/1); T4 (polpa, açúcar 0,6/0,4).

As notas atribuídas $(6,98$ a 7,58$)$ pelos provadores indicam uma faixa de aceitação entre o "gostei regularmente" e o "gostei muito".

Em relação ao odor, as notas variaram de 6,53 a 7,0 , sem diferença estatística significativa. Portanto, para os julgadores, o cheiro da geleia não teve interferência da matéria-prima utilizada, de polpa ou suco da acerola. Para as notas do atributo corte, apenas a formulação do tratamento T3 diferiu das demais, com o menor valor $(5,93)$. Os julgadores consideraram que a geleia tinha consistência macia ao cortar, sendo que as médias das notas ficaram entre "gostei ligeiramente" e "gostei muito". Isso pode ser explicado pelo equilíbrio encontrado na geleia entre a acidez e a concentração de açúcar, atingido no ponto final de sua cocção (ELEUTERIO, 1998).

Para o atributo espalhamento, também não foi observada diferença estatística entre tratamentos; no entanto, observou-se a maior nota de aceitação de 7,73 (T2), indicando a faixa de aceitação de "gostei muito". Segundo Torrezan (1997), a consistência da geleia é consequência de um equilíbrio entre dois fatores da estrutura, ou seja, a continuidade, ligada à concentração de pectina, e a rigidez, relacionada à concentração de açúcar e ácido.

O T4 obteve melhor aceitação do sabor $(7,08)$ do que o T3, enquanto os tratamentos 1 e 2 não diferiram entre si e nem de T3 e T4. A menor quantidade de açúcar adicionado pode ter favorecido o realce do sabor da fruta nessa formulação.

Para avaliação geral, os T2 e T4 obtiveram as maiores notas, sendo que os T1 e T3 não diferiram entre si e nem de T2.

Todas as formulações de geleia foram bem aceitas quanto aos atributos avaliados; no entanto, a amostra do T4 foi mais aceita do que T3 quanto ao corte e ao sabor.

\section{Conclusões}

As geleias elaboradas a partir de acerola apresentaram características físico-químicas adequadas à formação da consistência, demonstrando assim a possibilidade de sua utilização industrial, sem a adição de ácidos no processamento.

Em todos os aspectos sensoriais avaliados, os resultados foram desejáveis e obtiveram boa aceitabilidade, sendo possível afirmar que a formulação T3 (polpa, açúcar 1/1) apresentou menor aceitação quanto ao corte e ao sabor do que as demais.

\section{Agradecimentos}

À Fundação de Amparo à Pesquisa do Estado de São Paulo (FAPESP).

\section{Referências}

AGUIAR, L. P. $\beta$-Caroteno, Vitamina C e Outras Características de Qualidade de Acerola, Caju e Melão em Utilização no Melhoramento Genético. 2001. 87 f. Dissertação (Mestrado em Tecnologia de Alimentos)-Universidade Federal do Ceará, Fortaleza, 2001.

ARAGÃO, C.; IKEGAKI, L.; SATO, H.; OLIVEIRA, I. M.; PARK, Y. K. Determination of ascorbic acid concentration in acerola and camu-camu fruit juices by ascorbate oxidase method.

Boletim da Sociedade Brasileira de Ciência e Tecnologia de Alimentos, v. 16, n. 2, p. 175-176, 1996.

ASSIS, M. M. M. Processamento e estabilidade de geléia de caju. Revista Ciência Agronômica, Fortaleza, v. 38, n. 1 , p. 46-51, 2007.

BRASIL. Ministério da Saúde. Agência Nacional de Vigilância Sanitária. Métodos Físico-químicos para Análises de Alimentos. 4. ed. Brasília: Ministério da Saúde, 2005a. 1018 p. (Serie A. Normas e Manuais técnicos).

BRASIL. Ministério da Agricultura, Pecuária e Abastecimento. Instrução Normativa n. 24, de 08 de setembro de 2005. Aprova o Manual Operacional de Bebidas e Vinagres. Diário Oficial da República Federativa do Brasil, Brasília, DF, 20 set. 2005b. Seção 1, p. 11. Disponível em: <www.agricultura.gov.br>. Acesso em: 10 set. 2008.

CARPENTIERI-PÍPOLO, V.; PRETE, C. E. C.;GONZALEZ, M. G. N.; POPPER, I. O. Novas cultivares de acerola (Malpighia 
Característica físico-química e sensorial de geleia elaborada com polpa e suco de acerola CAETANO, P. K. et al.

emarginata DC) EUL3- Dominga, UEL4- Lígia e UEL5- Natália. Revista Brasileira de Fruticultura, Jaboticabal, v. 24, n. 1, p. 124-126, 2002. http://dx.doi.org/10.1590/S010029452002000100027

CHAVES, M. C. V.; GOUVEIA J. P. G.; ALMEIDA, F. A. C.; LEITE, J. C. A.; SILVA, F. L. H. Caracterização físico-química do suco da acerola. Revista de Biologia e Ciências da Terra, Campina Grande, v. 4, n. 2, p. 1-10, 2004.

CHITARRA, M. I. F.; CHITARRA, A. B. Pós-Colheita de Frutos e Hortaliças - Fisiologia e Manuseio. 2. ed. Lavras: ESAL/ FAEPE, 2005. 785 p.

COOPERATIVA CENTRAL DOS PRODUTORES DE AÇÚCAR E ÁlCOOL DO ESTADO DE SÃO PAULO - COPERSUCAR. Amostragem e Análise da Cana-de-açúcar. Piracicaba: COPERSUCAR, 1980. $37 \mathrm{p}$.

CARVALHO, R. A. Análise Econômica da Produção de Acerola no Município de Tomé-Açú, Pará. Belém: Embrapa Amazônia Oriental, 2000. 21 p. (Documento, n. 49).

DAMIANI, C.; VILAS BOAS, E. V. B.; SOARES, M. S. S. J.; CALIARI, M.; PAULA, M. L.; ASQUIERI, E. R. Avaliação química de geléias de manga formuladas com diferentes níveis de cascas em substituição a polpa. Revista Ciência e Agrotecnologia, Lavras, v. 33, n. 1, p. 177-184, 2009.

Eleuterio, R. M. C. Variação do Teor de Acido Ascórbico e de $\beta$-caroteno em Suco e Geléia de Acerola (Malpighia glabra L. - Sinônimo M. punicifolia L.) Durante - Armazenamento. 1998. 77 f. Dissertação (Mestrado)Universidade de São Paulo, Piracicaba, 1998.

GOMES, J. E.; PERECIN, D.; MARTINS, A. B. G.; FERRAUDO, A. S. Análise de agrupamentos de componentes principais no processo seletivo em genótipos de acerola (Malpighia emarginata D.C.). Revista Brasileira de Fruticultura, Jaboticabal, v. 22, n. 1, p. 36-39, 2000.

GORGATTI NETTO, A.; ARDITO, E. F. G.; GARCIA, E. E. C.; BLEINROTH, E. W.; FREIRE, F. C. O.; MENEZES, R.E. (Eds.). Acerola Exportação: Procedimentos de Colheita e Pós-Colheita. Brasília: EMBRAPA - SPJ, 1996. 30 p. (Série Publicação Técnica FRUPEX, n. 21).

GONZAGA NETO, L.; MATHUZ, B.; SANTOS, A. E. Caracterização agronômica de clones de aceroleira (Malpighia spp) na região do submédio São Francisco. Revista Brasileira de Fruticultura, Jaboticabal, v. 21, n. 2, p. 110-115, 1999.

JACKIX, M. H. Doces, Geléias e Frutas em Caldas: Teórico e Prático. Campinas: Editora da UNICAMP; São Paulo: Icone, 1988. $172 \mathrm{p}$.

KROLOW, A. C. R. Preparo Artesanal de Geleias e Geleiadas. Pelotas: Embrapa Clima Temperado, 2005. 29 p.

LAGO, E. S.; GOMES, E.; SILVA, R. Produção de geléia de Jambolão (syzygium cumini LAMARCK): Processamento, parâmetros físico-químicos e avaliação sensorial. Revista Ciência e Tecnologia de Alimentos, Campinas, v. 26, n. 4, p. 847-852, 2006. http://dx.doi.org/10.1590/S010120612006000400021

MÉLO, E. A. Formulação e avaliação físico-química e sensorial de geléia mista de pitanga (Eugenia uniflora L.) e acerola (Malpiglia sp). Botetim CEPPA, Curitiba, v. 17, n. 1, p. 33-44, 1999.

MUSTARD, M. J. The ascorbic acid content of some Malpighia fruit and jellies. Science, v. 104, p. 230-231, 1946. http://dx. doi. org/10.1126/science.104.2697.230

NIE, N. H.; HULL, C. H.; JEKINS, J. G.; STEINBRENNER, K., BENTE, D. SPSS: Statistical Package for the Social Sciences. 2. ed.New York: MCGraw-Hill, 1975.

NEGRETE, V. Desenvolvimento de Processo a Vácuo para Geléia de Acerola e Acompanhamento de Vida de Prateleira. 2001. 91 f. Dissertação (Mestrado em Tecnologia de Alimentos)-Faculdade de Engenharia de Alimentos, Universidade Estadual de Campinas, Campinas, 2001.

PAIVA, J. R.; ALVES, R. E.; SANTOS, F. J. S. Desempenho de clones de acerola no Estado do Ceará. In: CONGRESSO BRASILEIRO DE FRUTICULTURA, 17., 2002, Belém. Anais... Belém: SBF, 2002. CD-ROM.

SEMENSATO, L. R.; PEREIRA, A. S. Características de frutos de genótipos de aceroleira cultivados sob elevada altitude. Pesquisa Agropecuária Brasileira, Brasília, v. 35, n. 12, p. 2529-2536, 2000. http://dx.doi.org/10.1590/S0100204X2000001200024

SOLER, M. P. Industrialização de Geléias: Processamento Industrial. Campinas: Instituto de Tecnologia de Alimentos: ITAL, 1991. (Manual Técnico, n. 7).

TORREZAN, R. Preparo Caseiro de Geléias. Rio de Janeiro:Embrapa - CTAA, 1997. 15 p. 